\title{
Anesthetic management of video-assisted thoracoscopic surgery (VATS) in pediatric patients: the issue of safety in infant and younger children
}

\author{
Hyo-Jin Byon ${ }^{1}$, Ji-Won Lee ${ }^{1}$, Jong-Kuk Kim² ${ }^{2}$ Jin-Tae Kim ${ }^{1}$, Young Tae Kim ${ }^{3}$, Hee-Soo Kim ${ }^{1}$, \\ Sang Chul Lee ${ }^{1}$, and Chong Sung Kim ${ }^{1}$ \\ Department of Anesthesiology and Pain Medicine, ${ }^{1}$ Seoul National University College of Medicine, ${ }^{2}$ National Police Hospital, \\ ${ }^{3}$ Department of Thoracic and Cardiovascular Surgery, Seoul National University College of Medicine, Seoul, Korea
}

Background: The purpose of this study was to assess the safety issues concerning anesthetic management of videoassisted thoracoscopic surgery (VATS) in pediatric patients.

Methods: The medical records of 52 pediatric patients undergoing VATS using general anesthesia and one-lung ventilation $(\mathrm{OLV})$ were reviewed. OLV was achieved with a Fogarty catheter $(\mathrm{n}=23)$ or endobronchial intubation $(\mathrm{n}=7)$ in patients $<10$ years of age (group $\mathrm{Y}, \mathrm{n}=30)$, and using a double-lumen tube $(\mathrm{n}=19)$ or a univent $(\mathrm{n}=3)$ in children aged between 10 and 16 years of age (group $\mathrm{O}, \mathrm{n}=22$ ). Hypoxemia, hypercarbia, the difference between $\mathrm{E}_{\mathrm{T}} \mathrm{CO}_{2}$ and $\mathrm{PaCO}_{2}$, and the effect of $\mathrm{CO}_{2}$ insufflation were assessed.

Results: A decrease in $\mathrm{SpO}_{2}$ less than $90 \%$ was observed in $40 \%$ of the group Y, compared to none of the group O (P $<$ 0.05). A hypercarbia $\left(\mathrm{E}_{\mathrm{T}} \mathrm{CO}_{2}>50 \mathrm{mmHg}\right)$ was observed more frequently in group $\mathrm{Y}(40 \%)$ than in group $\mathrm{O}(0 \%$; $\mathrm{P}<$ 0.05). The difference between the $\mathrm{E}_{\mathrm{T}} \mathrm{CO}_{2}$ and $\mathrm{PaCO}_{2}$ was $10.4 \pm 8.9 \mathrm{mmHg}$ in group $\mathrm{Y}$ and $4.6 \pm 3.9 \mathrm{mmHg}$ in group $\mathrm{O}$ $(\mathrm{P}<0.05)$. Hypercarbia and acidosis occurred more frequently in patients with $\mathrm{CO}_{2}$ insufflation than those without insufflation in group $Y$.

Conclusions: Although the anesthesia for VATS in pediatric patients was successfully accomplished, the infants and younger children presented with more intra-operative problems when compared with older children. The anesthetic management for VATS in infants and younger children requires careful and vigilant monitoring. (Korean J Anesthesiol 2010; 59: 99-103)

Key Words: Children, One lung ventilation, Video-assisted thoracoscopic surgery.

Received: February 1, 2010. Revised: 1st, February 17, 2010; 2nd, March 31, 2010. Accepted: May 19, 2010.

Corresponding author: Jin-Tae Kim, M.D., Ph.D., Department of Anesthesiology and Pain Medicine, Seoul National University College of Medicine, 101, Daehak-ro, Jongno-gu, Seoul 110-744, Korea. Tel: 82-2-2072-3664, Fax: 82-2-745-5587, E-mail: kimjintae73@hotmail.com (c) This is an open-access article distributed under the terms of the Creative Commons Attribution Non-Commercial License (http:// creativecommons.org/licenses/by-nc/3.0/), which permits unrestricted non-commercial use, distribution, and reproduction in any medium, provided the original work is properly cited. 


\section{Introduction}

Video-assisted thoracoscopic surgery (VATS) has been in wide use recently for its many advantages such as minimal invasiveness, marked reduction in post-operative pain, faster recovery rate and superior cosmetic results [1]. Recently, the use of VATS in pediatric patients is increasing due to refinements in the technique, improvements in instrumentation, and advances in pediatric anesthesia [2-4]. However, VATS in infants and younger children still remains a challenge largely due to their small size and lower capacity. The anesthetic management in infants and younger children is more difficult than older children because of the following impediments: difficulty in one-lung ventilation $(\mathrm{OLV})$, carbon dioxide $\left(\mathrm{CO}_{2}\right)$ insufflation, hypothermia, and the effect of lateral decubitus position [5].

Many methods are available for OLV in pediatric patients, such as the double-lumen tube (DLT), univent tube, Arnt blocker, Fogarty catheter, and endobronchial intubation [6]. These options should be chosen according to the patient's size and availability. Special anesthetic techniques and devices for OLV are needed in infants and younger children because of a different respiratory anatomy and physiology compared with older children or adults.

Despite the increasing use of VATS and its potential problems, there are limited data on the safety concerns of anesthetic management for VATS in infants and younger children. The purpose of this study was to assess the safety implications of anesthetic management for VATS, focusing on hypoxemia, hypercarbia, hypothermia, and $\mathrm{CO}_{2}$ insufflation. This report details our experience with anesthetic management for VATS in pediatric patients with an analysis based on age.

\section{Materials and Methods}

This study was approved by the Institutional Review Board. The authors reviewed the medical records of 52 pediatric patients who underwent VATS between April 2006 and June 2009. During this period, all anesthesia and OLV were conducted according to the institutional protocol under the supervision of one anesthesiologist.

Anesthesia was induced with intravenous thiopental (6 mg/ $\mathrm{kg}$ ) and maintained with air/oxygen and sevoflurane. Muscle relaxation was achieved with rocuronium at an initial dose of $0.6 \mathrm{mg} / \mathrm{kg}$ with supplementary doses during the procedure. Electrocardiography, non-invasive blood pressure, pulse oxymerty $\left(\mathrm{SpO}_{2}\right)$, end tidal $\mathrm{CO}_{2}$ concentration $\left(\mathrm{E}_{\mathrm{T}} \mathrm{CO}_{2}\right)$ and body temperature were monitored. Arterial catheterization was performed for continuous blood pressure monitoring and blood sampling in 48 patients. $\mathrm{E}_{\mathrm{T}} \mathrm{CO}_{2}$ was measured by using side stream capnography (Smart Anesthesia Multi-gas Module,
GE Medical System Information Technologies, Inc., Milwaukee, WI, USA). All monitoring data were transferred automatically onto the electrical chart every 5 minutes. Arterial blood gas analysis (ABGA, GEM Premier 3000; Instrumental Laboratory, Lexington, MA, USA) was performed in patients who had an arterial line 10-30 min after the start of OLV.

OLV was used for all patients. Endobronchial intubation or a Fogarty embolectomy catheter (Edwards Lifesciences, Irvine, CA, USA) were used for OLV in patients $<7$ years of age. The endotracheal tube (ETT) was inserted into the main bronchus of the dependent lung under fiberoptic guidance (OD $2.2 \mathrm{~mm}$ or $3.1 \mathrm{~mm}$; Olympus LF-P or LF-DP, Olympus, Tokyo, Japan). The Fogarty catheter was advanced into the main bronchus of the non-dependent lung using fiberoptic bronchoscope. The size of the ETT and a Fogarty catheter was determined based on the size of the main bronchus on the computed tomography (CT) image and the proper size was confirmed by direct visualization under fiberoptic bronchoscopy. A specially designed adapter was used to facilitate administration of oxygen and ventilation during placement of a Fogarty catheter through the indwelling ETT [7].

The left bronchial DLT (Broncho-Cath ${ }^{\mathrm{TM}}$; Mallinckrodt Medical, Athlone, Ireland) or the univent tube (Fuji Systems Co., Tokyo, Japan) was used to perform OLV in children 10-16 years of age. The proper position of each device was confirmed again by auscultation and fiberoptic visualization after placing the patient in the lateral decubitus position. At the start of OLV, $100 \%$ oxygen was administered. Mechanical ventilation was adjusted at the attending anesthesiologist's discretion. Positive end expiratory pressure was not applied in all patients. $\mathrm{CO}_{2}$ was insufflated in 13 patients depending on the condition of lung collapse.

For the purpose of assessing the influence of age and method of OLV, the subjects were divided into group $\mathrm{Y}(<10$ years of age, $n=30)$ and group $\mathrm{O}(10-16$ years of age, $n=22)$. We compared the intra-operative data, such as $\mathrm{SpO}_{2}, \mathrm{E}_{\mathrm{T}} \mathrm{CO}_{2}, \mathrm{ABGA}$ data, discrepancy between $\mathrm{E}_{\mathrm{T}} \mathrm{CO}_{2}$ and $\mathrm{PaCO}_{2}\left(\mathrm{PaCO}_{2}-\mathrm{E}_{\mathrm{T}} \mathrm{CO}_{2}\right)$ and body temperature between groups $\mathrm{Y}$ and $\mathrm{O}$. To evaluate the effect of $\mathrm{CO}_{2}$ insufflation, these parameters were compared between the patients with and without $\mathrm{CO}_{2}$ insufflation in group $\mathrm{Y}$.

The differences between the groups were analyzed with an unpaired t-test, Mann-Whitney test, or chi-square test. A P value $<0.05$ was considered significant.

\section{Results}

The patients characteristics and surgical procedures are shown in Table 1 and 2. Fogarty catheter $(n=23)$ or mainstem bronchus intubation ( $\mathrm{n}=7$ ) was used for OLV in group Y, and doublelumen tube $(n=19)$ or univent $(n=3)$ was used in group $O$. 
Table 1. Patient Characteristics

\begin{tabular}{lcc}
\hline & Group Y $(\mathrm{n}=30)$ & Group O $(\mathrm{n}=22)$ \\
\hline Age (yr) & $2.9 \pm 2.1(0.3-7)$ & $13.1 \pm 1.8(10-16)^{*}$ \\
Weight $(\mathrm{kg})$ & $14.3 \pm 5.4(6.7-28.3)$ & $50.3 \pm 15.0(23.0-87.2)^{*}$ \\
Height (cm) & $95.3 \pm 17.5$ & $159.5 \pm 12.9$ \\
& $(67.8-128.8)$ & $(134.7-185.0)^{*}$ \\
Gender (M/F) & $15 / 15$ & $14 / 8$ \\
OLV (Right/Left) & $15 / 15$ & $11 / 11$ \\
Anesthetic time (min) & $186 \pm 94(70-475)$ & $177 \pm 90(90-330)$ \\
\hline
\end{tabular}

Values are presented as mean \pm SD (range) or number. Group Y: $<$ 10 years of age, Group O: 10-16 years of age, OLV: one lung ventilation. ${ }^{*} \mathrm{P}<0.05$ between the groups.

Table 2. Surgical Procedures of Patients

\begin{tabular}{lcc}
\hline & Group Y $(\mathrm{n}=30)$ & Group O $(\mathrm{n}=22)$ \\
\hline Plication & 4 & 0 \\
Biopsy & 5 & 6 \\
Lobectomy & 10 & 7 \\
Mass excision & 7 & 5 \\
Decortication & 3 & 0 \\
Wedge resection & 1 & 1 \\
Bullectomy & 0 & 3 \\
\hline
\end{tabular}

Values are presented as number. Group Y: $<10$ years of age, Group O: $10-16$ years of age.

Table 3. Parameters during Anesthesia

\begin{tabular}{lcc}
\hline & Group Y $(\mathrm{n}=30)$ & Group O (n=22) \\
\hline $\mathrm{SpO}_{2}<95 \%$ & $53 \%$ & $5 \% *$ \\
$\mathrm{SpO}_{2}<90 \%$ & $40 \%$ & $0 \% *$ \\
$\mathrm{Lowest}^{*} \mathrm{SpO}_{2}(\%)$ & $91 \pm 8(77-100)$ & $99 \pm 2(94-100)^{*}$ \\
$\mathrm{E}_{\mathrm{T}} \mathrm{CO}_{2}>50 \mathrm{mmHg}^{*}$ & $40 \%$ & $0 \%^{*}$ \\
$\mathrm{Highest}_{\mathrm{T}} \mathrm{CO}_{2}(\mathrm{mmHg})$ & $52 \pm 11(34-82)$ & $42 \pm 5(28-49)^{*}$ \\
Temperature $<36^{\circ} \mathrm{C}$ & $27 \%$ & $41 \%$ \\
Lowest temperature $\left({ }^{\circ} \mathrm{C}\right)$ & $36.0 \pm 0.6(34.8-37.0)$ & $36.0 \pm 0.5(35.2-37.0)$
\end{tabular}

Values are presented as mean \pm SD (range) or percentage. Group Y: $<10$ years of age, Group O: $10-16$ years of age. ${ }^{*} \mathrm{P}<0.05$ between the groups.

The parameters assessed during anesthesia are shown in Table 3. The incidence of desaturation occurred more frequently in group $\mathrm{Y}$ than in group $\mathrm{O}(\mathrm{P}<0.05)$, and the lowest value of $\mathrm{SpO}_{2}$ during surgery was significantly lower in group $\mathrm{Y}$ than group $\mathrm{O}(\mathrm{P}<0.05)$. A decrease in $\mathrm{SpO}_{2}$ usually occurred just after initiation of OLV, after suctioning the tube, or when the balloon of the Fogarty catheter was dislodged. However, desaturation at the start of OLV was recovered by manual ventilation within a few minutes. In addition, correction of the cause of hypoxemia improved $\mathrm{SpO}_{2}$. Hypercarbia $\left(\mathrm{E}_{\mathrm{T}} \mathrm{CO}_{2}>50\right.$ $\mathrm{mmHg}$ ) occurred more frequently in group $\mathrm{Y}$ than group $\mathrm{O}(\mathrm{P}$ $<0.05)$. There were no significant differences in the incidence of hypothermia and the lowest temperature between the two groups. There was no significant difference in the use of inotropics between the groups.
Table 4. Arterial Blood Gas Analysis during One Lung Ventilation

\begin{tabular}{lcc}
\hline & Group Y $(\mathrm{n}=24)$ & Group O $(\mathrm{n}=14)$ \\
\hline $\mathrm{pH}$ & $7.30 \pm 0.09(7.15-7.47)$ & $7.40 \pm 0.07(7.25-7.48)^{*}$ \\
$\mathrm{PaO}_{2}(\mathrm{mmHg})$ & $192.8 \pm 100.0(66-399)$ & $270.2 \pm 58.9(150-400)^{*}$ \\
$\mathrm{PaCO}_{2}(\mathrm{mmHg})$ & $51.7 \pm 13.9(32-86)$ & $39.0 \pm 5.6(30-51)^{*}$ \\
$\mathrm{PaCO}_{2}-\mathrm{E}_{\mathrm{T}} \mathrm{CO}_{2}$ & $10.4 \pm 9.0(-6-39)$ & $4.6 \pm 3.9(1-16)^{*}$ \\
$\quad(\mathrm{mmHg})$ & &
\end{tabular}

Values are presented as mean \pm SD (range). Group Y: $<10$ years of age, Group O: $10-16$ years of age. ${ }^{*} \mathrm{P}<0.05$ between the groups.

Table 5. Patient Characteristics in Patients under 7-year-old

\begin{tabular}{lcc}
\hline & $\begin{array}{c}\text { Patients with } \mathrm{CO}_{2} \\
\text { insufflation }(\mathrm{n}=13)\end{array}$ & $\begin{array}{c}\text { Patients without } \mathrm{CO}_{2} \\
\text { insufflation }(\mathrm{n}=17)\end{array}$ \\
\hline Age (yr) & $2.2 \pm 2.0(0.5-7)$ & $3.5 \pm 2.1(0.3-7)$ \\
Weight $(\mathrm{kg})$ & $12.1 \pm 3.7(8.7-20.3)$ & $16.0 \pm 6.0(6.7-28.3) *$ \\
Height $(\mathrm{cm})$ & $88.6 \pm 14.9(71-118.9)$ & $101.2 \pm 18.0(67.8-128.8)$ \\
Gender (M/F) & $9 / 4$ & $6 / 11$ \\
\hline
\end{tabular}

Values are presented as mean \pm SD (range) or number. $* \mathrm{P}<0.05$ between the groups.

Table 6. Parameters during Anesthesia in Patients under 7-year-old

\begin{tabular}{lcc}
\hline & $\begin{array}{c}\text { Patients with } \mathrm{CO}_{2} \\
\text { insufflation }(\mathrm{n}=13)\end{array}$ & $\begin{array}{c}\text { Patients without } \mathrm{CO}_{2} \\
\text { insufflation }(\mathrm{n}=17)\end{array}$ \\
\hline $\mathrm{SpO}_{2}<95 \%$ & $62 \%$ & $47 \%$ \\
$\mathrm{SpO}_{2}<90 \%$ & $54 \%$ & $29 \%$ \\
${\mathrm{Lowest} \mathrm{SpO}_{2}(\%)}_{\mathrm{E}_{\mathrm{T}} \mathrm{CO}_{2}>50 \mathrm{mmHg}}^{88 \pm 8(77-100)}$ & $93 \pm 7(78-100)$ \\
$\mathrm{Highest} \mathrm{E}_{\mathrm{T}} \mathrm{CO}_{2}(\mathrm{mmHg})$ & $60 \pm 11(42-82)$ & $18 \%$ \\
Temperature $<36^{\circ} \mathrm{C}$ & $23 \%$ & $45 \pm 6(34-59)^{*}$ \\
Lowest Temperature $\left({ }^{\circ} \mathrm{C}\right)$ & $36.1 \pm 0.7(35.0-37.0)$ & $35.9 \pm 0.6(34.8-36.8)$ \\
\hline
\end{tabular}

Valuesare presented as mean $\pm \mathrm{SD}$ (range) or percentage. $* \mathrm{P}<0.05$ between the groups.

Table 7. Arterial Blood Gas Analysis in Patients under 7-year-old

\begin{tabular}{lcc}
\hline & $\begin{array}{c}\text { Patients with } \mathrm{CO}_{2} \\
\text { insufflation }(\mathrm{n}=9)\end{array}$ & $\begin{array}{c}\text { Patients without } \mathrm{CO}_{2} \\
\text { insufflation }(\mathrm{n}=15)\end{array}$ \\
\hline $\mathrm{pH}$ & $7.21 \pm 0.04(7.15-7.28)$ & $7.35 \pm 0.06(7.22-7.47)^{*}$ \\
$\mathrm{PaO}_{2}(\mathrm{mmHg})$ & $162 \pm 89(67-298)$ & $211 \pm 104(66-399)$ \\
$\mathrm{PaCO}_{2}(\mathrm{mmHg})$ & $64 \pm 13(52-86)$ & $44 \pm 8(32-64)^{*}$ \\
$\mathrm{PaCO}_{2}-\mathrm{E}_{\mathrm{T}} \mathrm{CO}_{2}$ & $16 \pm 12(2-39)$ & $17 \pm 5(-6-13)^{*}$ \\
$(\mathrm{mmHg})$ & &
\end{tabular}

$\overline{\text { Values are presented as mean } \pm \mathrm{SD} \text { (range). }{ }^{*} \mathrm{P}<0.05 \text { between the }}$ groups.

The results of ABGA during OLV are shown in Table 4. $\mathrm{E}_{\mathrm{T}} \mathrm{CO}_{2}$ in group $\mathrm{Y}$ tended to underestimate the $\mathrm{PaCO}_{2}$ compared with the group $\mathrm{O}(\mathrm{P}<0.05)$. The $\mathrm{pH}$ was lower in group $\mathrm{Y}$ than group $\mathrm{O}$, whereas $\mathrm{PCO}_{2}$ was higher in group $\mathrm{Y}$ than group $\mathrm{O}(\mathrm{P}<0.05)$.

$\mathrm{CO}_{2}$ was insufflated in 13 patients in group $\mathrm{Y}$ and in no patients in group $\mathrm{O}$ (Table 5). The group $\mathrm{Y}$ data according to $\mathrm{CO}_{2}$ insufflation are shown in Table 6 and $7 . \mathrm{CO}_{2}$ insufflation was required in lighter patients in group Y. There were more 
incidences of hypercarbia, acidosis, and increased $\mathrm{PaCO}_{2}$ $\mathrm{E}_{\mathrm{T}} \mathrm{CO}_{2}$ in patients with $\mathrm{CO}_{2}$ insufflation than without $\mathrm{CO}_{2}$ insufflation. There was no difference in the use of inotropics between the patients with $\mathrm{CO}_{2}$ insufflation and without $\mathrm{CO}_{2}$ insufflation in group $\mathrm{Y}$.

Two cases of Fogarty catheter balloon dislodgement and 1 case of endobronchial tube withdrawal into the trachea occurred during surgical manipulation; however, it was immediately repositioned into a mainstem bronchus under guidance of a fiberoptic bronchoscope. The operative condition is described as poor in 4 patients 6 months to 4 years of age, including 2 cases of Fogarty balloon dislodgement and 1 case of endobronchial tube withdrawal.

Post-operatively, there were no significant complications, such as bronchial rupture, brain damage, bleeding needing reoperation, and severe pulmonary dysfunction in any of the patients.

\section{Discussion}

VATS was accomplished without significant complications in all the patients, but hypoxemia and hypercapnia were the more commonly observed events in infants and younger children compared with older children.

Although OLV is not mandatory for all VATS procedures, it is considered extremely desirable for VATS in pediatric patients. However, OLV in infants and younger children seem to be more difficult than OLV in adolescents and adults for anatomic and physiologic reasons. A previous study showed that majority of the patients, particularly infants and younger children, needed two-lung ventilation for VATS because of intolerance [8]. In younger children, ventilation/perfusion mismatch associated with hypoxemia is more prominent in the lateral decubitus position because ventilation to the dependent lung is impeded by the compression of the dependent hemithorax due to a more compliant rib cage. The small thorax reduces the beneficial effect of the hydrostatic pressure gradient between the non-dependent and dependent lungs [6]. In infants, the functional residual capacity is closer to the residual volume, making airway closure likely to occur in the dependent lung. In addition, oxygen consumption is higher than in adults. A small lumen tube is easily obstructed by blood or secretions. A low safety margin of device displacement can also predispose to hypoxemia.

In this study Fogarty catheter was used for OLV in group Y. The size of the Fogarty catheter was determined based on the diameter of the main bronchus on the pre-operative CT and chest X-ray. The anterior-posterior diameter of the main bronchus was measured on CT or the vertical diameter was measured on chest X-ray. In addition, inflation of the balloon was adjusted to match the size of the main bronchus under direct bronchoscopic exam. CT images were also helpful to choose the size of the ETT for endobronchial intubation.

We placed the Fogarty catheter through, rather than alongside the ETT, thus enabling repositioning of the balloon when it was displaced. However, the Fogarty catheter through the ETT decreased the lumen of the ETT and possibly caused an undesirable effect on ventilation. In addition, a Fogarty catheter for OLV had several problems. The pressure of the inflating balloon is high enough to cause damage ranging from a mucosal injury to bronchial rupture [9]. Therefore, excessive ballooning for perfect OLV should be avoided. Another problem is that Fogarty catheter does not have an end hole for suction or continuous positive airway pressure, which may cause atelectasis of the operated lung. Additionally, the trachea is sometimes needed to suction before inflating the Fogarty balloon so as to deflate the lungs fast and effectively. However, selective suction of the lung to be operated is very difficult, so both lungs were deflated simultaneously when the ETT was suctioned. This can predispose the more susceptible patient to hypoxemia. Therefore, it is advisable to ventilate the lungs with $100 \%$ oxygen before OLV to facilitate lung deflation and prevent hypoxemia [10].

This study also highlighted that hypercarbia $\left(\mathrm{E}_{\mathrm{T}} \mathrm{CO}_{2}>50\right.$ $\mathrm{mmHg}$ ) was more frequently observed in infants and younger children, which is in agreement with a previous study [11]. The possible causes of a high $\mathrm{E}_{\mathrm{T}} \mathrm{CO}_{2}$ in infants and younger children can be hypoventilation, $\mathrm{CO}_{2}$ insufflation, and malpositioning of the device. As pneumoperitoneum is established during laparoscopy, younger children absorb proportionately more $\mathrm{CO}_{2}$ than older individuals [12]. The $\mathrm{CO}_{2}$ insufflation causes hypercarbia and acidosis, but not hypoxemia during VATS in children [13] the data herein confirm these results.

The discrepancy between $\mathrm{E}_{\mathrm{T}} \mathrm{CO}_{2}$ and $\mathrm{PaCO}_{2}$ was also higher in the group $\mathrm{Y}$. Therefore, the $\mathrm{E}_{\mathrm{T}} \mathrm{CO}_{2}$ on the monitor can underestimate the arterial $\mathrm{CO}_{2}$, especially in infants and younger children. The ABGA is useful to detect masked acidosis and hypercarbia in younger children undergoing OLV.

Infants and younger children are more susceptible to hypothermia during thoracospcopy [5]. However, another study reported that thoracoscopy was associated with an increase in core temperature intra-operatively [10]. In our study, there was no difference in the incidence of hypothermia between the groups. However, body temperature should be monitored during VATS in pediatric patients to avoid possible hypothermia and hyperthermia.

In conclusion, appropriate preparation and careful management enables performing VATS in pediatric patients without significant complications. The frequent occurrence of hypoxemia and hypercapnia in infants and younger children 
demands special attention for performing VATS in infants and younger children.

\section{References}

1. Haynes SR, Bonner S. Review article: anaesthesia for thoracic surgery in children. Paediatr Anaesth 2000; 10: 237-51.

2. Rothenberg SS. First decade's experience with thoracoscopic lobectomy in infants and children. J Pediatr Surg 2008; 43: 40-4.

3. Albanese CT, Rothenberg SS. Experience with 144 consecutive pediatric thoracoscopic lobectomies. J Laparoendosc Adv Surg Tech A 2007; 17: 339-41.

4. Cano I, Antón-Pacheco JL, García A, Rothenberg S. Video-assisted thoracoscopic lobectomy in infants. Eur J Cardiothorac Surg 2006; 29: 997-1000.

5. Gentili A, Lima M, De Rose R, Pigna A, Codeluppi V, Baroncini S. Thoracoscopy in children: anaesthesiological implications and case reports. Minerva Anestesiol 2007; 73: 161-71.

6. Choudhry DK. Single-lung ventilation in pediatric anesthesia. Anesthesiol Clin North America 2005; 23: 693-708.

7. Kim JT, Yoon TG, Kim HS, Kim CS, Kim SD. Simple multiport adaptor for selective lung ventilation in pediatric patients. Anesth Analg 2007; 105: 892.

8. McGahren ED, Kern JA, Rodgers BM. Anesthetic techniques for pediatric thoracoscopy. Ann Thorac Surg 1995; 60: 927-30.

9. Borchardt RA, LaQuaglia MP, McDowall RH, Wilson RS. Bronchial injury during lung isolation in a pediatric patient. Anesth Analg 1998; 87: 324-5.

10. Ko R, McRae K, Darling G, Waddell TK, McGlade D, Cheung K, et al. The use of air in the inspired gas mixture during two-lung ventilation delays lung collapse during one-lung ventilation. Anesth Analg 2009; 108: 1092-6.

11. McHoney M, Mackinlay G, Munro F, Capek A, Aldridge L. Effect of patient weight and anesthetic technique on $\mathrm{CO}_{2}$ excretion during thoracoscopy in children assessed by end-tidal $\mathrm{CO}_{2}$. J Laparoendosc Adv Surg Tech A 2008; 18: 147-51.

12. McHoney M, Corizia L, Eaton S, Kiely EM, Drake DP, Tan HL, et al. Carbon dioxide elimination during laparoscopy in children is age dependent. J Pediatr Surg 2003; 38: 105-10.

13. Mukhtar AM, Obayah GM, Elmasry A, Dessouky NM. The therapeutic potential of intraoperative hypercapnia during videoassisted thoracoscopy in pediatric patients. Anesth Analg 2008; 106 : 84-8. 